\title{
Erratum to: Monetary policy challenges: how central banks changed their modus operandi
}

\section{Giorgio Di Giorgio ${ }^{1}$}

Published online: 9 July 2015

(C) Eurasia Business and Economics Society 2015

\section{Erratum to: Eurasian Econ Rev (2014) 4:25-43 DOI 10.1007/s40822-014-0002-5}

On page 34, Fig. 5 'Composition of central banks' balance sheets', the legend has been published illegibly or incompletely. The author has provided a clearer illustration below (Fig. 5) to replace the published version.

This mistake happened during the production process of the article and unfortunately remained unnoticed. The publisher apologises for this mistake.
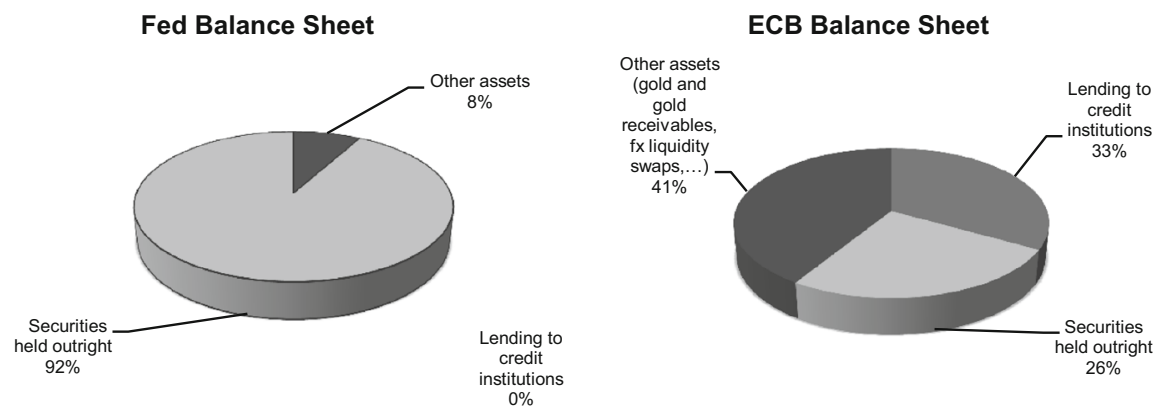

Fig. 5 Composition of central banks' balance sheets. Source: St. Louis Fed, European Central Bank

The online version of the original article can be found under doi:10.1007/s40822-014-0002-5.

Giorgio Di Giorgio

gdg@luiss.it

1 Department of Economics and Finance, Arcelli Center for Monetary and Financial Studies, Università LUISS, Rome, Italy 